Check for updates

Cite this: RSC Adv., 2018, 8, 39731

Accepted 21st November 2018

DOI: $10.1039 / c 8 r a 08925 f$

rsc.li/rsc-advances

\section{Racemic vs. enantiopure inert Ti(Iv) complex of a single diaminotetrakis(phenolato) ligand in anticancer activity toward human drug-sensitive and -resistant cancer cell lines $\dagger$}

\author{
Maya Miller and Edit Y. Tshuva (iD * \\ A tetrakis(phenolato) Ti(Iv) complex was synthesized in racemic and optically pure form, exhibiting high \\ hydrolytic stability, and similar cytotoxicity for all stereochemical forms on HT-29 and A2780 cancer \\ cells. Higher activity of the racemate on drug-resistant A2780cp and A2780adr lines implies a beneficial \\ activity of both enantiomers rendering enantiomeric resolution unnecessary.
}

First presented by Köpf-Maier in the 1970s, titanium compounds have shown promise as metallodrugs for cancer treatment. $^{\mathbf{1 , 2}}$ Wide research exploring different chelating ligands for $\mathrm{Ti}(\mathrm{Iv})$ for anticancer applications started with diketonato- and cyclopentadienyl-based moieties. ${ }^{2-14}$ Despite low toxicity and high efficacy observed in in vivo models for the two parent Ti(Iv) compounds titanocene dichloride and budotitane, they failed in clinical trials due to insufficient efficacy to toxicity ratio. ${ }^{15-17}$ The main drawback of the Ti(Iv) compounds lies in their rich hydrolytic chemistry, leading to decomposition to give multiple clusters in the biological environment, which eventually hampered the complexes' medical utility. ${ }^{\mathbf{6}, 18,19}$

Our group has introduced the highly potent and hydrolytically stable Ti(Iv) complexes of phenolato ligands. ${ }^{20}$ The first generation of compounds was based on a tetradentate diamino bis(phenolato) chelating scaffold with two alkoxo labile ligands, which showed in vitro activity in a wide range of cell lines, in vivo efficacy, and enhanced hydrolytic stability.,20-35 Importantly, some defined highly inert polynuclear hydrolysis products, obtained within hours following labile ligand hydrolysis, exhibited high cytotoxic activity, confirming that labile ligands are not essential for the cytotoxic effect. ${ }^{21,28,36,37}$ Following studies focused on potent inert mononuclear Ti(Iv) complexes lacking labile ligands $;^{38,39}$ particularly, mono-ligated Ti(Iv) complexes of hexadentate diaminotetrakis(phenolato) or diaminobis(phenolato)-bis(alkoxo) ligands showed high antineoplastic effect as well as exceptionally high hydrolytic stability. ${ }^{37,40,41}$

Institute of Chemistry, The Hebrew University of Jerusalem, Jerusalem 9190401, Israel. E-mail: edit.tshuva@mail.huji.ac.il

$\dagger$ Electronic supplementary information (ESI) available: Complete experimental details and characterization data are provided in ESI. CCDC 1858443. For ESI and crystallographic data in CIF or other electronic format see DOI: 10.1039/c8ra08925f
Most phenolato Ti(Iv) compounds reported thus far are chiral $\left(C_{1^{-}}\right.$or $C_{2}$-symmetrical), therefore the biological evaluation of the pure enantiomers and comparison with their racemic mixture is appropriate. ${ }^{\mathbf{4 2 , 4 3}}$ Previous stereochemical studies included diaminobis(phenolato) "salan" type ligands with chiral cyclohexyl or bipyrrolidine moieties for chiral at metal induction. ${ }^{\mathbf{4 4 - 4 8}}$ The different behaviour observed for racemic mixture compared with those of its pure enantiomers was attributed to the generation of active disatereomeric (homochiral or hetero-chiral) clusters in water solution, exhibiting different cellular reactivity.

In this paper, we present a new highly inert chiral Ti(Iv) complex, based on a single diaminotetrakis(phenolato) chiral ligand, synthesized as racemic $(\Lambda+\Delta)$ and as optically pure $(\Lambda$, $\Delta)$ by ligand to metal chiral induction. The hydrolytic stability abolishes the formation of diastereomeric clusters, and thus the enantiomers could be compared with the racemate as their $1: 1$ innocent mixture.

Aiming to develop a highly stable mono-ligated Ti(Iv) complex in an enantiopure form, a cyclohexanediaminotetraki$\mathrm{s}$ (phenolato) $\mathrm{Ti}(\mathrm{Iv})$ complex was synthesized according to a published procedure. ${ }^{49}$ Pure enantiomers ( $\Delta$ or $\Lambda$ at metal) were obtained through ligand-to-metal chiral induction from optically pure trans-1,2-diaminocyclohexane $(R, R$ or $S, S$ at ligand, respectively); the corresponding racemate $(\Delta+\Lambda$ at metal) was similarly obtained starting from the racemic form of the starting material.

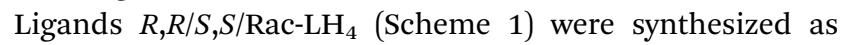
previously described, ${ }^{49}$ reacting trans-diaminocyclohexane with 2,2'-dihydroxybenzophenone in methanol, followed by reduction with $\mathrm{NaBH}_{4}$. The ligands were characterized by ${ }^{1} \mathrm{H}$ and ${ }^{13} \mathrm{C}$ NMR, optical rotation, circular dichroism (CD), and high resolution mass spectroscopy (HRMS), all demonstrating similar features to those of previously reported systems. ${ }^{49}$ The corresponding $\operatorname{Ti}(\mathrm{IV})$ complexes (Scheme 1) were produced by 


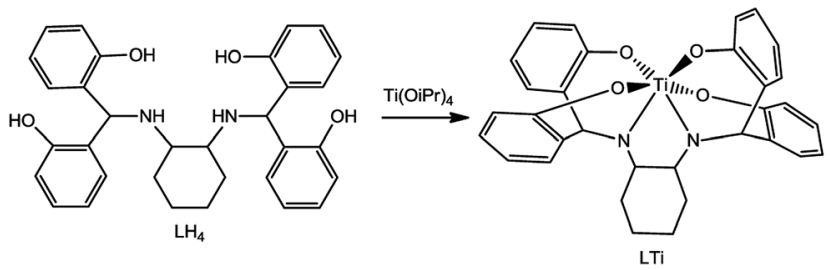

Scheme 1

reacting $\mathrm{LH}_{4}$ with $\mathrm{Ti}\left(\mathrm{O}^{\mathrm{i}} \mathrm{Pr}\right)_{4}$ in $\mathrm{THF}$, at room temperature, overnight. The yellow precipitant that formed spontaneously was isolated by decantation. ${ }^{1} \mathrm{H}$ NMR spectra confirmed formation of the desired symmetrical products with eight signals for the aromatic region and a corresponding set of aliphatic signals. The complexes were also characterised by optical rotation, CD, and HRMS.

Single crystals of $S, S, \Lambda$-LTi obtained from dichloromethane at ambient temperature were analyzed by X-ray crystallography (Fig. 1). The structure features a distorted octahedral complex of a $C_{2}$ symmetry, with similar coordination features as those of its enantiomer $R, R, \Delta$-LTi previously reported. ${ }^{49}$ The Ti-O bond lengths are similar, 1.85 and $1.91 \AA$ as reported for related structures. ${ }^{41}$ The Ti-N length of $2.21 \AA$ is typical to secondary amine coordination. ${ }^{44,47,48}$ The high deviation from octahedral symmetry is clearly pronounced by the $\mathrm{O}(2)^{\prime}-\mathrm{Ti}-\mathrm{N}(1)$ and $\mathrm{O}(2)-$ $\mathrm{Ti}-\mathrm{O}(2)^{\prime}$ angles, with values of $161.5(1)^{\circ}$ and $112.5(2)^{\circ}$, respectively. ${ }^{41}$

The hydrolytic stability was assessed using ${ }^{1} \mathrm{H}$ NMR based on previously reported procedures. ${ }^{21,28}$ About $3.6 \mathrm{mM}$ of $S, S, \Lambda$-LTi was dissolved in DMSO, $\mathrm{H}_{2} \mathrm{O}(>10000$ equivalents) was added to give a $90 \%$ water solution, and the mixture was allowed to stand for 17 days. The solvents were then removed and the ${ }^{1} \mathrm{H}$ NMR spectrum was recorded in DMSO- $d_{6}$ (Fig. 2). No decomposition under these conditions was observed, confirming high water stability despite the rather strained structure obtained in the solid state.

The cytotoxicity of the complexes was analyzed towards human colon HT-29, as well as human ovarian sensitive A2780, cisplatin-resistant A2780cp, and adriamycin-resistant A280adr

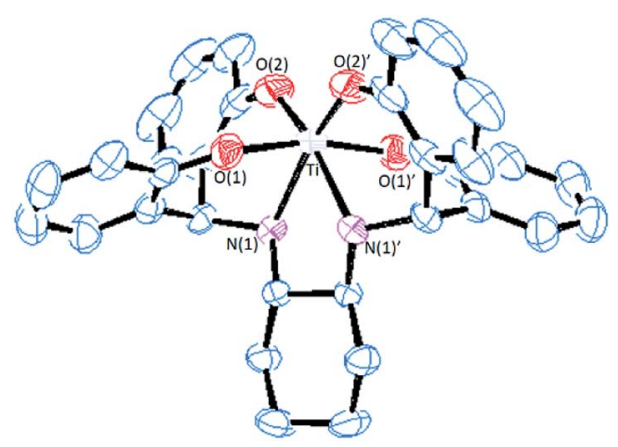

Fig. 1 ORTEP presentations of S,S, $\Lambda$-LTi with $50 \%$ probability ellipsoids; $\mathrm{H}$ atoms were omitted for clarity. Selected bond lengths $[\AA]$ and angles [ ${ }^{\circ}$ ]: O(1)-Ti: 1.913(2), O(2)-Ti: 1.845(2), N(1)'-Ti: 2.208(2); O(2)$\mathrm{Ti}-\mathrm{O}(2)^{\prime}:$ 112.5(2), O(2)-Ti-O(1)': 92.4(1), O(2)-Ti-O(1): 94.5(1), O(1)'$\mathrm{Ti}-\mathrm{O}(1):$ 167.5(1), O(2)-Ti-N(1): 85.5(1), O(2)'-Ti-N(1): 161.5(1), O(1)'$\mathrm{Ti}-\mathrm{N}(1): 88.4(1), \mathrm{O}(1)-\mathrm{Ti}-\mathrm{N}(1): 81.8(1), \mathrm{N}(1)-\mathrm{Ti}-\mathrm{N}(1)^{\prime}:$ 76.9(1).
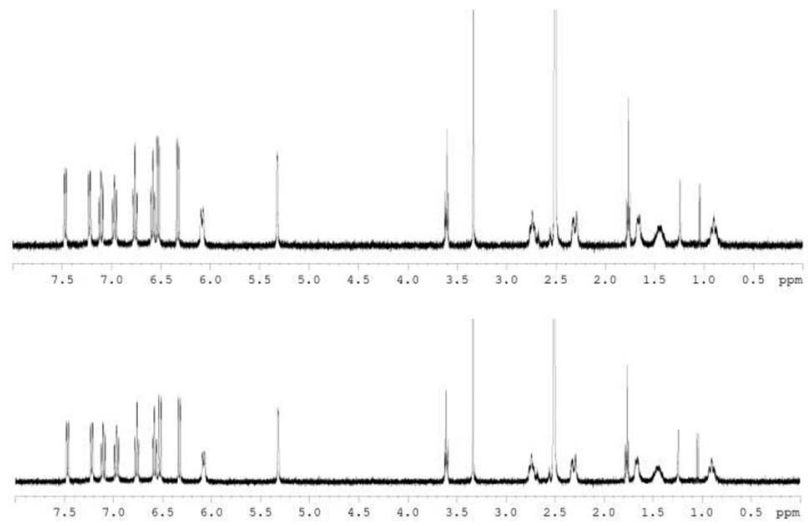

Fig. $2{ }^{1} \mathrm{H}$ NMR spectra for S,S, $\Lambda$ - LTi in DMSO- $d_{6}$, before (top) and 17 days after (bottom), the addition of $90 \% \mathrm{H}_{2} \mathrm{O}$ (spectrum of the latter taken in neat DMSO- $d_{6}$ following evaporation).

cancer cell lines. The viability was measured by the methylthiazolyldiphenyl-tetrazolium (MTT) assay as previously described.$^{\mathbf{5 0}}$ The results are illustrated in Fig. 3.

When inspecting the parent lines HT-29 and A2780 (Fig. 3, top), moderate activity was recorded for all stereochemical forms. This moderate activity may be attributed to the large steric bulk of the complex (Fig. 1), often hampering biological accessibility as was observed previously with other diamino tetrakis(phenolato) complexes being cytotoxic only once formulated in nano-particles to enhance solubility and cell penetration ability. ${ }^{36,37,40}$ Importantly, no significant difference in cytotoxicity was observed for the two enantiomers, $R, R, \Delta$ - and $S, S, \Delta-\mathrm{LT}$, a result similar to previous observations with chiral complexes of salan ligands. ${ }^{44,45,47,48}$ Nevertheless, according to the high hydrolytic stability of LTi, and unlike previous observations with less stable salan-based Ti(rv) complexes, the racemic mixture indeed behaves as expected of a simple $1: 1$ mixture of enantiomers, with similar reactivity to that of the
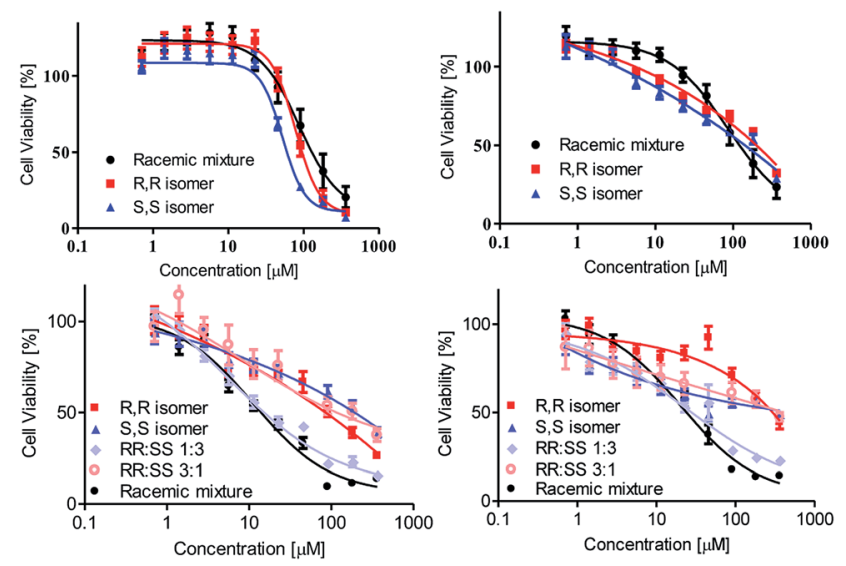

Fig. 3 Dependence of HT-29 (top left), A2780 (top right), A2780cp (bottom left) and A2780adr (bottom right) cell viability based on the MTT assay following a three days incubation period on added concentration of various stereochemical mixtures of $\mathrm{LTi}$, presented on a logarithmic scale. Relative $\mathrm{IC}_{50}$ of rac-LTi on HT-29, A2780, A2780cp, and A2780adr: $77.9 \pm 13.3,78.8 \pm 19.1,14.6 \pm 5.0$, and $13.1 \pm$ $1.8 \mu \mathrm{M}$, respectively. 
pure forms, without decomposition to active diastereomeric clusters. These observation overall challenge the conception of direct interaction with chiral target as the main mode of action, ${ }^{46}$ while suggesting that tedious separation of the pure enantiomers may not be of necessity for utilization of phenolato Ti(Iv) compounds as anticancer remedy. ${ }^{\mathbf{4 4 , 4 5 , 4 7 , 4 8}}$ Interestingly, when inspecting the reactivity of the complexes toward the drug resistant lines A2780cp and A280adr (Fig. 3, bottom) the racemic mixture is clearly more active than found on the parent line, and more active than the pure forms. Applying mixtures of different ratios of the two enantiomers showed that small excess ( $\sim 3: 1$ ratio) of the $\Lambda$ isomer retains the maximal cytotoxic effect as observed for the racemic mixture, whereas similar excess ( $\sim 1: 3$ ratio) of $\Delta$ enantiomer reduces the activity back to the values obtained for pure enantiomers. Due to the high hydrolytic stability of the complex, formation of heterochiral clusters with particular ratios of chiral centres cannot serve as a plausible explanation. Thus, it is possible that the two enantiomers operate on different cellular processes, which may be influenced in the resistant lines. Alternatively, effect on drug transport may also be considered. For example, ATP-binding cassette $(\mathrm{ABC})$ proteins, which are expressed in both resistant cell lines, ${ }^{52}$ play a role in uptake and efflux of cytotoxic metal compounds, ${ }^{51}$ and could also be relevant to the Ti(Iv) complexes. Additionally, the two enantiomers administered together can be subjected to drug-drug interaction relationship, which was shown to play some role in drug absorption where $\mathrm{P}$ glycoprotein (of an ABC family) plays a major part. ${ }^{53}$ Additional studies are therefore required to elucidate the particular effect of both isomers.

\section{Conclusions}

This paper presents the first hydrolytically stable mono-ligated anticancer $\mathrm{Ti}(\mathrm{Iv})$ complex, synthesized and analysed as pure enantiomers. In vitro studies on colon and ovarian cell lines show similarly moderate cytotoxicity of all stereochemical forms, whereas for drug resistant lines, preference for the $\Lambda$ enantiomer implies some beneficial activity of both isomers. The results altogether emphasize the advantage of utilizing racemic mixture over pure enantiomers for $\mathrm{Ti}(\mathrm{Iv})$ phenolato compounds.

\section{Conflicts of interest}

There are no conflicts to declare.

\section{Acknowledgements}

We thank Dr Benny Bogoslavsky for solution of the X-ray structure. Funding was received from the European Research Council (ERC) under the European Union's Horizon 2020 research and innovation programme (grant agreement 681243).

\section{Notes and references}

1 H. Köpf and P. Köpf-Maier, Angew. Chem., Int. Ed. Engl., 1979, 18, 477-478.

2 E. Y. Tshuva and M. Miller, in Metallo-Drugs, Development and Action of Anticancer Agents, 2018, pp. 219-249.

3 P. Manohari Abeysinghe and M. M. Harding, Dalton Trans., 2007, 3474-3482.

4 E. Y. Tshuva and D. Peri, Coord. Chem. Rev., 2009, 253, 20982115.

5 M. E. Heim, H. Flechtner and B. K. Keppler, Ruthenium and Other Non-Platinum Metal Complexes in Cancer Chemotherapy. Progress in Clinical Biochemistry and Medicine, ed. E. Baulieu, et al., Springer, Berlin, Heidelberg, 1989, vol. 10, pp. 217-223.

6 I. Kostova, Anti-Cancer Agents Med. Chem., 2009, 9, 827-842.

7 M. Cini, T. D. Bradshaw and S. Woodward, Chem. Soc. Rev., 2017, 46, 1040-1051.

8 K. M. Buettner and A. M. Valentine, Chem. Rev., 2012, 112, 1863-1881.

9 K. Strohfeldt and M. Tacke, Chem. Soc. Rev., 2008, 11741187.

10 P. Koepf-Maier and H. Koepf, Chem. Rev., 1987, 87, 11371152.

11 F. Caruso, M. Rossi and C. Pettinari, Expert Opin. Ther. Pat., 2001, 11, 969-979.

12 F. Caruso and M. Rossi, Met. Ions Biol. Syst., 2004, 353-384.

13 B. K. Keppler, C. Friesen, H. G. Moritz, H. Vongerichten and E. Vogel, in Bioinorganic Chemistry, Springer Berlin Heidelberg, Berlin, Heidelberg, 1991, pp. 97-127.

14 E. Y. Tshuva and J. A. Ashenhurst, Eur. J. Inorg. Chem., 2009, 2203-2218.

15 C. V. Christodoulou, D. R. Ferry, D. W. Fyfe, A. Young, J. Doran, T. M. T. Sheehan, A. Eliopoulos, K. Hale, J. Baumgart, G. Sass and D. J. Kerr, J. Clin. Oncol., 1998, 2761-2769.

16 G. Lümmen, H. Sperling, H. Luboldt, T. Otto and H. Rübben, Cancer Chemother. Pharmacol., 1998, 42, 415-417.

17 T. Schilling, K. B. Keppler, M. E. Heim, G. Niebch, H. Dietzfelbinger, J. Rastetter and A. R. Hanauske, Invest. New Drugs, 1996, 13, 327-332.

18 J. H. Toney and T. J. Marks, J. Am. Chem. Soc., 1985, 107, 947953.

19 F. Caruso, L. Massa, A. Gindulyte, C. Pettinari, F. Marchetti, R. Pettinari, M. Ricciutelli, J. Costamagna, J. C. Canales, J. Tanski and M. Rossi, Eur. J. Inorg. Chem., 2003, 3221-3232.

20 M. Shavit, D. Peri, C. M. Manna, J. S. Alexander and E. Y. Tshuva, J. Am. Chem. Soc., 2007, 12098-12099.

21 D. Peri, S. Meker, C. M. Manna and E. Y. Tshuva, Inorg. Chem., 2011, 1030-1038.

22 T. A. Immel, M. Debiak, U. Groth, A. Bürkle and T. Huhn, ChemMedChem, 2009, 4, 738-741.

23 A. Tzubery and E. Y. Tshuva, Inorg. Chem., 2011, 50, 79467948.

24 A. Tzubery and E. Y. Tshuva, Inorg. Chem., 2012, 51, 17961804. 
25 A. Tzubery and E. Y. Tshuva, Eur. J. Inorg. Chem., 2017, 16951705.

26 D. Peri, C. M. Manna, M. Shavit and E. Y. Tshuva, Eur. J. Inorg. Chem., 2011, 4896-4900.

27 S. Barroso, A. M. Coelho, S. Gomez-Ruiz, M. J. Calhorda, Z. Zizak, G. N. Kaluderovic and A. M. Martins, Dalton Trans., 2015, 44, 2497.

28 D. Peri, S. Meker, M. Shavit and E. Y. Tshuva, Chem.-Eur. J., 2009, 15, 2403-2415.

29 H. Glasner and E. Y. Tshuva, J. Am. Chem. Soc., 2011, 133, 16812-16814.

30 H. Glasner and E. Y. Tshuva, Inorg. Chem., 2014, 53, 31703176.

31 C. M. Manna, O. Braitbard, E. Weiss, J. Hochman and E. Y. Tshuva, ChemMedChem, 2012, 703-708.

32 T. A. Immel, U. Groth, T. Huhn and P. Öhlschläger, PLoS One, 2011, 6, e17869.

33 T. A. Immel, U. Groth and T. Huhn, Chem.-Eur. J., 2010, 2775-2789.

34 M. Miller, O. Braitbard, J. Hochman and E. Y. Tshuva, J. Inorg. Biochem., 2016, 163, 250-257.

35 S. Meker, C. M. Manna, D. Peri and E. Y. Tshuva, Dalton Trans., 2011, 40, 9802-9809.

36 S. Meker, K. Margulis-Goshen, E. Weiss, S. Magdassi and E. Y. Tshuva, Angew. Chem., Int. Ed., 2012, 51, 10515-10517.

37 S. Meker, K. Margulis-Goshen, E. Weiss, O. Braitbard, J. Hochman, S. Magdassi and E. Y. Tshuva, ChemMedChem, 2014, 9, 1294-1298.

38 A. D. Tinoco, H. R. Thomas, C. D. Incarvito, A. Saghatelian and A. M. Valentine, Proc. Natl. Acad. Sci. U. S. A., 2012, 109, 5016-5021.
39 T. A. Immel, M. Gruzke, A.-K. Spae, U. Groth, P. Hlschlaer and T. Huhn, Chem. Commun., 2012, 48, 5790-5792.

40 S. Meker, O. Braitbard, K. Margulis-Goshen, S. Magdassi, J. Hochman and E. Y. Tshuva, Molecules, 2015, 20, 1852618538.

41 S. Meker, O. Braitbard, M. D. Hall, J. Hochman and E. Y. Tshuva, Chem.-Eur. J., 2016, 22, 9986-9995.

42 M. Cini, H. Williams, M. W. Fay, M. S. Searle, S. Woodward and T. D. Bradshaw, Metallomics, 2016, 8, 286-297.

43 I. De La Cueva-Alique, L. Muñoz-Moreno, Y. Benabdelouahab, B. T. Elie, M. A. El Amrani, M. E. G. Mosquera, M. Contel, A. M. Bajo, T. Cuenca and E. Royo, J. Inorg. Biochem., 2016, 156, 22-34.

44 C. M. Manna, G. Armony and E. Y. Tshuva, Inorg. Chem., 2011, 50, 10284-10291.

45 C. M. Manna, G. Armony and E. Y. Tshuva, Chem.-Eur. J., 2011, 17, 14094-14103.

46 C. M. Manna and E. Y. Tshuva, Dalton Trans., 2010, 39, 11821184.

47 M. Miller and E. Y. Tshuva, Eur. J. Inorg. Chem., 2014, 14851491.

48 M. Miller and E. Y. Tshuva, Sci. Rep., 2018, 8, 9705.

49 M. S. Seo and H. Kim, J. Am. Chem. Soc., 2015, 137, 1419014195.

50 N. Ganot, S. Meker, L. Reytman, A. Tzubery and E. Y. Tshuva, J. Visualized Exp., 2013, e50767.

51 S. Spreckelmeyer, C. Orvig and A. Casini, Molecules, 2014, 19, 15584-15610.

52 M. P. Ween, M. A. Armstrong, M. K. Oehler and C. Ricciardelli, Crit. Rev. Oncol. Hematol., 2015, 96, 220-256. 53 J. H. Lin, Adv. Drug Delivery Rev., 2003, 55, 53-81. 